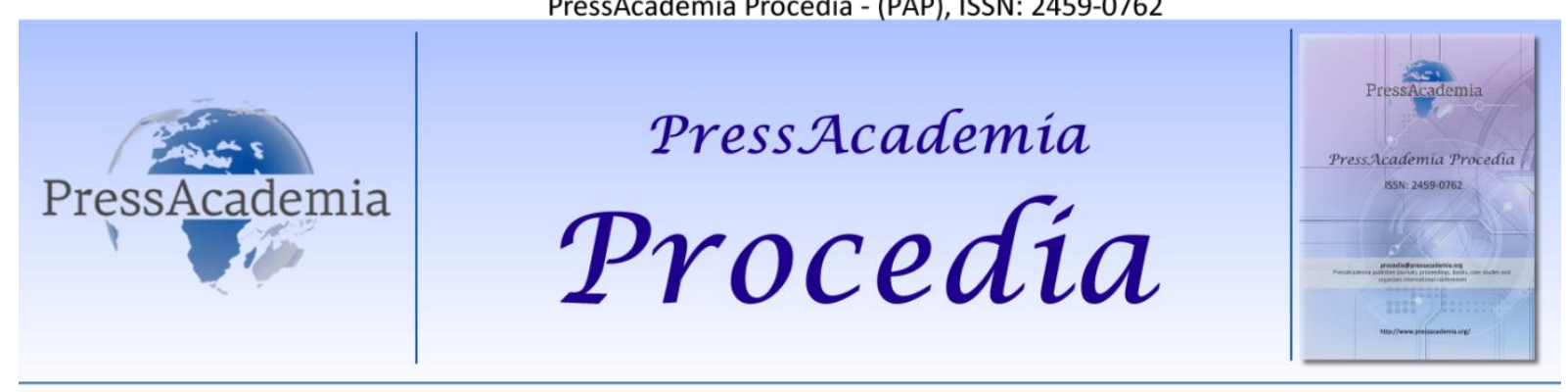

2nd World Conference on Technology, Innovation and Entrepreneurship

May 12- 14, 2017, Istanbul, Turkey. Edited by Sefer Şener

\title{
INNOVATIONS IN THE BIODIESEL PRODUCTION
}

\author{
DOI: 10.17261/Pressacademia.2017.566 \\ PAP-WCTIE-V.5-2017(4)--p.24-28
}

Emine Emel Cakirca ${ }^{1}$, Ayse Nilgün Akin ${ }^{1}$

${ }^{1}$ Kocaeli University, Engineering Faculty. emel.cakirca@kocaeli.edu.tr

\begin{abstract}
Demand on energy from alternative fuels are growing rapidly due to depletion of fossil fuels and global warming crises. Biodiesel instead of conventional petroleum diesel, is a non toxic, biodegradable and renewable fuels. Therefore, biodiesel can be considered as a promising liquid fuel for transport sector. Among the routes of biodiesel synthesis, the most commonly used are transesterification of oil feedstocks and esterification of free fatty acids, in which these are carried forward in the presence of a catalyst. In transesterification process, a large majority of feedstocks come from vegetable/edible oil, as the first generation biodiesel feedstocks, in many regions of the world. The use of edible oils is not convenient in production of biodiesel due to insufficient amount of edible oil feedstocks and demand for food materials in the world. When it is thought that over $70 \%$ of price of biodiesel includes cost of feedstocks, use of cheaper and more sustainable resources have become inevitable. Waste cooking oil and algae oil, which have not been used as food sources, are termed as second generation feedstocks and seem more attractive and promising for biodiesel production. In addition to raw material source, the type of alcohol and catalyst also affects to price and quailty of biodiesel. Since biodiesel is a process includes sustainable technology, all inputs are investigated in terms of usability, sustainability and eco-friendly. The aim of this study to give an overwive on the biodiesel production in that select of the most effective and available feedstocks and summarize the recent development and innovation in the production process.
\end{abstract}

Keywords: Biodiesel, raw materials, oil, catalyst, innovation

\section{INTRODUCTION}

In recent decades, increasing human population and industrialization around the world led to depletion of fossil fuels and emergence of energy crisis. Furthermore scarcity of fossil fuels reserves and occurrence greenhouse gases through the use of fossil fuels have made alternative fuel resources more attractive for the future. Among the renewable energy resources, biodiesel is the most common alternative energy instead of conventional diesel. Biodiesel has gained attention recently due to its biodegradability, lack of sulphur, non toxisity, renewability and positive properties compared to petroleum diesel (Avhad and Marchtti, 2016; Tabatabaei et al., 2015).

It is derived from transesterification and esterification of edible or non edible oil and animal fats with short chain alcohols such as methanol and ethanol in presence of a catalyst. As shown in Figure 1, transesterification is a multi-step reaction; Triglycerides are converted to diglycerides, diglycerides are converted to monoglycerides and then monoglycerides are converted into biodiesel and glycerine as by-product. There are three important inputs in this reaction. The oil source that accounts for majority of biodiesel cost; the second is the type of catalyst that accelerates the reaction and improves biodiesel efficiency, and finally the alcohol sources.

The most widely used type of catalyst in the commercial production of biodiesel is homogeneous basic catalysts, $\mathrm{KOH}$ and $\mathrm{NaOH}$. Methanol is used as a reactant because of its cheap and easy availability. A wide variety of edible cooking oils are used as an oil source such as sunflower oil and canola oil for commercial production of biodiesel. In this study, recent studies and innovations in biodiesel production have been reviewed and summarized through the raw material sources. 
Figure 1: General Equation of Transesterification (Lima et al., 2016)

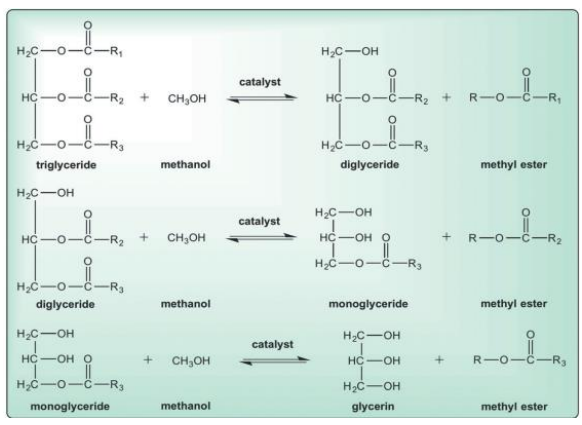

\section{RAW MATERIALS FOR BIODIESEL PRODUCTION}

Transesterification process is one of the most widely used method in the commercial production of biodiesel. This reaction takes place between triglycerides with alcohols having 1-8 carbon atoms in the presence of a catalyst. The raw materials for biodiesel production are triglycerides and short chain alcohols. In addition to them, catalysts also play an important role in transesterification reaction. It can be concluded that there are three major materials which affect on biodiesel production in that its quality and cost. Among these materials, oil feedstock is the most important one since it plays decisive role in terms of cost of biodiesel.

\subsection{Oil Feedstocks}

Currently, majority of the biodiesel production is from edible oil (more than 95\%) (Ahmia et al., 2014). Table 1 shows classification of sources of biodiesel. In generally, oil sources are categorized in three groups: edible oil as 1st generation, non edible oil as second generation and other sources.

Table 1: Classification of the Raw Materials for Biodiesel Production (Verma et al., 2016)

\begin{tabular}{lll}
\hline Edible oil (1st generation) & Non edible oil (2nd generation) & Other sources (3rd generation) \\
\hline Soybean oil & Jatropha oil & Waste cooking oil \\
Rapeseed oil & Jojoba oil & Fish oil \\
Sunflower oil & Rubber seed oil & Microalgae \\
Palm oil & Milk bush oil & Animal fats \\
Canola oil & Linseed oil & Chicken fat oil \\
Corn oil & Neem oil & \\
Castor oil & Tall oil & \\
\hline
\end{tabular}

Leading countries around the world for biodiesel production are USA, Brazil, Germany, France and Argentina. In the US, soybean oil is still the largest biodiesel raw material. In Europe, canola oil is primary raw material in 2015. Rapeseed in Canada and palm oil in Southeast Asia are also used in biodisel production (Falch et al., 2016; Ahmia et al., 2014). The choise of raw materials for biodiesel depends on some parameters: (1) avail-ability of land, (2) cultivation practices, (3) energy supply and balance, (4) greenhouse gases, (5) logistics costs, (6) soil erosion and fertility, (7) direct economic value of the feedstocks (Bhuiya et al., 2016). Since rapeseed produced so much as to export in Europe, is commonly used in Europe in biodiesel production. Likewise, US and the other countries also use edible oils in the production of biodiesel, which are available for production on their own soil (Verma et al., 2016). However, usage of edible oil for production biodiesel competes with the use of land for food production and lead to increasing price of oil and causes food scarcity all over the world (Mardhiah et al., 2017; Chehetri et al, 2008, Verma et al., 2016). Non edible oil sources needs to be provided in biodiesel production for economical and environmental benefits. New generation biodiesel also known 2nd generation, produced from non edible oil such as Jatropha oil, microalgae oil or waste cooking oil. Utilization of renewable feedstocks provide sustainability for biodiesel and reduce the cost of biodiesel production by $60-90 \%$ (Baskar et al., 2016). Although microalgae and waste cooking oil are seen other sources as 3 rd generation from Table 1, these sources are also regarded as the 2nd generation biodiesel feedstocks in literature (Bhuiya et al., 2016).

Microalgae as new generation raw materials for biodiesel is an important alternative due to be able to grow in any environmental conditions and its high oil yields. Microalgae can play an important role in solving the problem between the production of food and biofuels in the near future. The advantages of microalgal biodiesel are : (1) contains no sulpur, (2) non toxic, (3) highly bio-degradable, (4) reduce carbon emissions (Demirbaş et al., 2011). Petvoy et al. (2012) reported that despite of the fact that algal biomass converted into their esters, algal biomass is much more expensive to produce 
biodiesel. So, researchs on the algal biodiesel focused on the economic viability of the algal biomass. From literature, it is seen that algal biodiesel will be one of the most important alternative fuels as long as it is economically healing.

One of the other promising raw material is waste cooking oil which has high potential for biodiesel production. Research shows that about 380,000 tonnes of waste cooking oil are produced in the US and 700,000 - 1,000,000 tonnes / year in Europe. Approximately 1.7 million tons of vegetable oil is consumed annually in Turkey, and a serious waste oil is generated (http://www.cygm.gov.tr). By using these oils as biodiesel resources, undesirable contaminant wastes are removed in an environmentally friendly way, while at the same time the dependence on edible resources in biofuel production will be reduced (Maneerung et al., 2016; Mohammadshirazi et al., 2014). Al-Hamamre et al. (2014) reported that the use of edible oils in biodiesel production affects approximately $70-95 \%$ of the cost of biodiesel. Therefore, minimizing the cost of raw material is a very important advantage for cheap and effective fuel production.

\subsection{Alcohol Feedstocks}

Transesterification is a reversible reaction and contains stoichiometrically 3: 1 alcohol to oil. However, excess alcohol is used in the reaction since using of excess alcohol pushes the reaction towards the products. Methanol as a cheap alcohol source is widely used because of its physical and chemical properties suitable for transesterification. But methanol has a low boiling point and the risk of explosion is very high. Methanol and methoxide are very dangerous substances that must be handled with care (Stamenkovic et al., 2011). Because of this, ethanol can be seen as an alternative to methanol due to its easy production and availability (Anastopoulos et al., 2013). The use of ethanol instead of methanol in the transesterification reaction is a promising step because it can be produced from agricultural renewable sources and has less toxicity than methanol.

\subsection{Catalysts For Biodiesel Production}

Transesterification is carried out by catalytically in order to increase reaction rate. Homogeneous catalysts such as $\mathrm{NaOH}$, $\mathrm{KOH}, \mathrm{H} 2 \mathrm{SO} 4$ are applied in conventional commercial methods. These type of catalysts have high yield in a short time in transesterification reaction. However, the steps such as washing and purification in homogeneous process increase the production cost. In addition, by using homogeneous catalysts it is seen that presence of $\mathrm{K} / \mathrm{Na}$ traces in the biodiesel and reduce product quality (Semwal et al., 2011). The main disadvantage of homogeneous catalysts is generation of large scale waste water from the washing process. For these reasons, research have been based on new technologies in terms of enviromentally, economically and reducing problems just mentioned.

According to free fatty acid contents of oil, asidic or basic catalysts are used. The amount of free fatty acids content in the oil is the determining parameter for the use of acidic or basic catalyst. When the free fatty acid content is too high, the use of basic catalyst causes the formation of soap, which is undesirable (Endalew et al., 2011). On the contrary, it is suitable to use an acidic catalyst in this case. But the reaction rate is quite slow.

One of the recent developments in the production of biodiesel is the design of heterogeneous catalysts that are more active, produced from alternative cheaper feedstocks and to be reusable.

The most important advantage of heterogeneous catalysts is lifetime of the catalysts which is longer than homogeneous catalysts in biodiesel production. This feature is related to stability of the crystal structure which of the catalytic surface. The poisoning and leaching of the catalyst during the reaction led to change the physical properties as well as deactivation of the catalyst. For this reason the catalyst must be properly formulated (Yan et al., 2010).

Table 2. shows that effect of the different type of oil, catalyst and alcohol on the biodiesel production. As it seen, heterogeneous catalysts exhibit competitive activity with homogeneous catalysts. CaO-based catalysts are widely used because of their long lifetime, exhibit high activity, and operate under moderate reaction conditions. CaO has also attracted attention due to obtained from waste, eggshell and mollusk shells in natural and inexpensive ways (Borgez et al., 2012).

Table 2: Summary of Raw Materials Used in Biodiesel Production in the Literature

\begin{tabular}{|c|c|c|c|c|c|}
\hline Process & Catalysts & Type of oil & Type of alcohol & Yield, \% & References \\
\hline Homogeneous & $\mathrm{KOH}$ & Freshwater algae & Ethanol & - & $\begin{array}{l}\text { Vijayaraghavan } \\
\text { et al., } 2009\end{array}$ \\
\hline Homogeneous & $\mathrm{H} 2 \mathrm{SO} 4$ & Microalgae & Methanol & - & $\begin{array}{l}\text { Miao et al., } \\
2006\end{array}$ \\
\hline Homogeneous & $\mathrm{NaOH}, \mathrm{KOH}$ & Frying oil & Ethanol & 74 & $\begin{array}{l}\text { Encinar et al., } \\
2007\end{array}$ \\
\hline Heterogeneous & MgFe2O4@CaO & Soybean oil & Methanol & 89 & Liu et al., 2016 \\
\hline Heterogeneous & $\mathrm{CaMgO}$ & Rapeseed oil & Methanol & 85 & Zakaria et al., \\
\hline
\end{tabular}




\begin{tabular}{|c|c|c|c|c|c|}
\hline & & & & & 2012 \\
\hline Heterogeneous & Mg-Al hydrotalcite & poultry fat & Methanol & 98 & $\begin{array}{l}\text { Liu et et al., } \\
2007\end{array}$ \\
\hline Heterogeneous & Lipaz & Palm oil & Ethanol & 82 & $\begin{array}{l}\text { Raita et al., } \\
2010\end{array}$ \\
\hline Heterogeneous & $\mathrm{Li}-\mathrm{CaO}$ & Jatropha curcas oil & Methanol & 100 & $\begin{array}{l}\text { Endalew et al., } \\
2011\end{array}$ \\
\hline Heterogeneous & Dolomite & Canola oil & Methanol & 92 & İlgen, 2011 \\
\hline Heterogeneous & $\mathrm{Ca} / \mathrm{Al} / \mathrm{Fe} 304$ & Rapeseed oil & Methanol & 98 & $\begin{array}{l}\text { Tang et al, } \\
2012\end{array}$ \\
\hline Heterogeneous & rice husk & Many kinds of oils & Methanol & 94 & $\begin{array}{l}\text { Roschat et al., } \\
2016\end{array}$ \\
\hline
\end{tabular}

\section{CONCLUSION}

Biodiesel is produced under different conditions by using a wide variety of oil feedstocks. But physical properties, environmental and economic efficiency of the oil are important effects on biodiesel production. The importance of biodiesel raw materials is inevitable especially considering the environmental and economic consequences. For this reason microalgae oil and waste oil are promising as future generation raw materials for biodiesel production. The current studies are about increasing the oil yield of microalgae and making them more commercially viable. Using waste oils in the production of biodiesel draws attention due to the fact that wastes are disposed as an environmentally friendly way and dependence on edible oils is reduced considerably as well. Alcohol, another raw material in biodiesel production, is based on methanol and ethanol in the literature. Ethanol has advantages over methanol because it can be biologically produced. But the ethanolysis reaction has not yet been fully investigated. Heterogeneous catalysts used in transesterification attract attention because of their being environment friendly, easy to find, reusable and cheap.

\section{REFERENCES}

Ahmia, A.C., Danane, F., Bessah, R., Boumesbah, I. 2014, “Raw material for biodiesel production”, vol. 17, no 2, pp. 335-343.

Al-Hamamre, Z., Yamin, J. 2014, "Parametric study of the alkali catalyzed transesterification of wast frying oil for Biodiesel production", Energy Conversion and Management, vol. 79, pp. 246-254.

Anastopoulos, G., Dodos, G.S., Kalligeros, S., Zannikos, F. 2013, “Biodiesel Production by Ethanolysis of Various Vegetable Oils Using Calcium Ethoxide as a Solid Base Catalyst", International Journal of Green Energy, vol. 10, pp. 468-481.

Avhad, M.R. and Marchtti, J.M. 2016, "Innovation in solid heterogeneous catalysis for the generation of economically viable and ecofriendly biodiesel: A review”, vol. 58, no 2, pp. 157-208.

Baskar, G., Aiswarya, R. (2016), "Trends in catalytic production of biodiesel from various feedstocks", Renewable and Sustainable Energy Reviews, vol. 57, pp. 496-504.

Bhuiya, M.M.K., Rasul, M.G., Khan, M.M.K., Ashwath N., Azad, A.K. (2016), "Prospects of 2nd generation biodiesel as a sustainable fuelPart: 1 selection of feedstocks, oil extraction techniques and conversion Technologies", Renewable and Sustainable Energy Reviews, vol. 55, pp. 1109-1128.

Chhetri, A.B., Watts, K.C., Islam, M.R. 2008, “Waste Cooking Oil as an Alternate Feedstock for Biodiesel Production”, Energies, vol. 1, pp. 318, DOI: $10.3390 /$ en1010003.

Demirbaş, A., Demirbaş, M. F. 2011, “Importance of algae oil as a source of biodiesel”, Energy Conversion and Management, vol. 52, pp. 163-170.

Encinar, J.M., González, J.F., Rodríguez-Reinares, A. 2007, "Ethanolysis of used frying oil. Biodiesel preparation and characterization", Fuel Processing Technology, vol. 88, pp. 513-522.

Endalew, A.K., Kiros, Y., Zanzi, R. 2011, “Heterogeneous catalysis for biodiesel production from Jatropha curcas oil (JCO)” Energy , vol. 36, pp. 2693-2700.

Flach, B., Lieberz, S., Rondon, M., Williams, B., Wilson, C. 2016, “EU Biofuels Annual 2016 “, pp. 22-29.

İlgen, O. 2011, "Dolomite as a heterogeneous catalyst for transesterification of canola oil”, Fuel Processing Technology, vol. 92, pp. 452455.

Lima, A.L.; Ronconi, C.M., Mota, C.J.A. 2016, "Heterogeneous basic catalysts for biodiesel production", Catalysis Science and Technology, vol. 6, pp. 2877-2891. 
Liu, Y., Zhang, P., Fan, M., Jiang, P. 2016, "Biodiesel production from soybean oil catalyzed by magnetic nanoparticle MgFe2O4@CaO", Fuel, vol. 164, pp. 314-321.

Maneerung, T., Kawi, S., Dai Y., Wang, C. 2016, "Sustainable biodiesel production via transesterification of waste cooking oil by using CaO catalysts prepared from chicken manure", Energy Conversion and Management, vol. 123, pp. 487-497.

Mardhiah, H. H., Ong, H.C., Masjuki, H.H., Lim, S., Lee, H.V. 2017, "A review on latest developments and future prospects of heterogeneous catalyst in biodiesel production from non-edible oils", Renewable and Sustainable Energy Reviews, vol.67, pp. 1225-1236.

Miao, M., Wu, Q. 2006, “Biodiesel production from heterotrophic microalgal oil”, Bioresource Technology, vol. 97, pp. 841-846.

Mohammadshirazi, A., Akram, A., Rafiee, S., Kalhor, E.B. 2014, "Energy and cost analyses of biodiesel production from waste cooking oil", Renewable and Sustainable Energy Reviews, vol. 33, pp. 44-49.

Petkov, G., Ivanova, A., Iliev, I., Vaseva, I. 2012, "A critical look at the microalgae biodiesel”, Eur. J. Lipid Sci. Technol.,vol. 114, pp. 103111.

Raita, M., Champreda, V., Laosiripojana, L. 2010, "Biocatalytic ethanolysis of palm oil for biodiesel production using microcrystalline lipase in tert-butanol system", Process Biochemistry, vol. 45, pp. 829-834.

Roschat, W., Siritanon, T., Yoosuk, B., Promarak, V. 2016, "Rice husk-derived sodium silicate as a highly efficient and low-cost basic heterogeneous catalyst for biodiesel production", Energy Conversion and Management, vol. 119, pp. 453-462.

Semwal, S., Arora, A.K., Badoni, R.P., Tuli, D.K. 2011,"Biodiesel production using heterogeneous catalysts", Bioresource Technology, vol. 102, pp. 2151-2161.

Stamenkovic, O. S., Velickovic, A.V., Veljkovic, V.B. 2011, “The Production Of Biodisel From Vegatable Oils by Ethanolysis: Current State and Perspectives", Fuel, vol. 90, pp. 3141-3155.

Tang, S., Wang, L., Zhang, Y., Li, S., Tian, S., Wang, B. 2012, "Study on preparation of Ca/Al/Fe 304 magnetic composite solid catalyst and its application in biodiesel transesterification", Fuel Processing Technology, vol. 95, pp. 84-89.

Tabatabaei, M., Karimi, K., Horváth, I. S., Kumar, R. 2015, “Recent trends in biodiesel production”, Biofuel Research Journal, vol. 7, pp. 258267.

Verma, P., Sharma, M.P., Dwivedi, G., 2016, “Impact of alcohol on biodiesel production and properties”, vol.56, pp. 319-333.

Vijayaraghavan, K., Hemanathan, K. 2009, “Biodiesel Production from Freshwater Algae”, Energy Fuels, vol. 23, pp. 5448-5453.

Yan, S., DiMaggio, C., Mohan, S., Kim, M., Salley, S.O., Simon Ng, K.Y. 2010, "Advancements in Heterogeneous Catalysis for Biodiesel Synthesis", Top Catal, vol. 53, pp. 721-736.

Zakaria, R., Harvey, A.P. 2012, "Direct production of biodiesel from rapeseed by reactive extraction/in situ transesterification", Fuel Processing Technology, vol. 102, pp. 53-60.

http://www.cygm.gov.tr/CYGM/Files/yayinlar/kitap/bitkisel atik yaglarin yonetimi kitapcigi.pdf 